\title{
The Impact of Graduate Student's Perceptions towards Usage of Cloud Computing in Higher Education Sectors
}

\author{
T. Ananthi Claral Mary, P. J. Arul Leena Rose* \\ Department of Computer Science, Faculty of Science and Humanities, SRM Institute of Science \& Technology, India
}

Received July 26, 2020; Revised September 7, 2020; Accepted September 29, 2020

\section{Cite This Paper in the following Citation Styles}

(a): [1] T. Ananthi Claral Mary, P. J. Arul Leena Rose, "The Impact of Graduate Student's Perceptions towards Usage of Cloud Computing in Higher Education Sectors," Universal Journal of Educational Research, Vol. 8, No. 11, pp. 5463 5478, 2020. DOI: 10.13189/ujer.2020.081150.

(b): T. Ananthi Claral Mary, P. J. Arul Leena Rose (2020). The Impact of Graduate Student's Perceptions towards Usage of Cloud Computing in Higher Education Sectors. Universal Journal of Educational Research, 8(11), 5463 - 5478. DOI: 10.13189/ujer.2020.081150.

Copyright@2020 by authors, all rights reserved. Authors agree that this article remains permanently open access under the terms of the Creative Commons Attribution License 4.0 International License

\begin{abstract}
Learning is a continuous process. Nowadays, students learn through digital technologies. The important factors that make education a distant dream are unavailability of educational resources and the high cost that comes with it. Cloud computing can solve both the issues. Cloud computing in education is a rapidly emerging technology. The individuals and the educational organizations are ready to adapt to new technologies. The usage of cloud computing technologies has modified the work flow of teachers, educators in higher education sectors. The adoption rate is gradually increasing due to its cost efficiency and collaborative nature of the educational cloud. The foremost objective of this paper is to determine the impact of graduate student's perceptions towards cloud technologies usage in higher education sectors and to examine its benefits to students and teachers. Powerful solutions provided by cloud applications have been proposed which will be beneficial to the higher education institutions. This empirical study analyzed and discussed the student's learning experience by using the cloud applications and services. The outcome of this study implies that the intention of respondents has endurance in using cloud computing services.
\end{abstract}

Keywords Cloud Computing, Framework, Point-to-Point Networks, Higher Education Institutions

\section{Introduction}

Cloud computing has become the key source of service and distribution. To help understand about the current transition into the world of computing, we have to think about where we have been, where we are now and why we have travelled these paths. During the primary age the emphasis was on mainframes, point-to-point networks, databases which are centralized and batch job. The next age of computing is the growth of Internet. There were innovations in architectures of software. Google became dominant in third age. The data collection and processing had to be automated as possible. Data storage is required to be done in a simple and consistent way. Operations needed are towards being automatic and reliable.

The internet and technologies of cloud computing inspire the foreseeing of a learning structure which employs cloud technologies to support the ease of learning materials and to report the problems of traditional education systems. Cloud computing supports collaborative and remote learning. The cloud computing environment has been converted the basic curriculum in universities. It offers low price result to higher education sectors for the students, teachers and scholars to improve their learning performance. An important gain of cloud technologies is the ability of sharing the large quantity of learning materials within and outside the educational sectors. 


\subsection{Enabling Techniques of Cloud Computing}

Figure 1 shows the enabling techniques of cloud computing. They are:

Virtualization: It is creation of a new virtual version of any product or service. E.g., disk partitions in hard drives that we use in our computer system for storage. We can have only one physical hard disk, but we can create two, three or more partitions virtually.

Parallel and Distributed Computing: When more than two processors work simultaneously to solve one problem, the technique is called parallel computing. It is the responsibility of the programmer to split the problems into pieces and relate each piece with the other. In cloud computing instead of parallelism, virtualization is used which adds a new layer in the existing system known as the virtualization layer. All computing trends are originally related to the concept of distributed computing. Therefore distributed computing is the key notion behind all the latest computing paradigms.

Web Service: It allows applications to communicate through the internet. APIs (Application Programming Interface) allow one program to speak with another. APIs and web services cannot be seen by the users. They run silently and do their work.

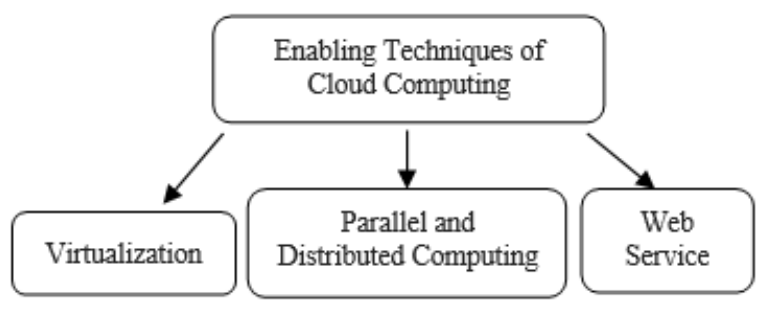

Figure 1. Enabling Techniques of Cloud Computing

\subsection{Cloud Education}

In the world of education cloud-based learning is the new buzz concept. Heart of it is the suppleness, it provides to create, distribute and collaborate from anywhere, anytime, any location. Several institutions have already embraced to create flexible educational environments using cloud computing. The characteristics of cloud computing in Education are:

\subsubsection{Storing \& Sharing}

Limitless storage capacity is provided by cloud which enables the educators to store and share their learning resources to students. Files can be updated and shared on the cloud.

\subsubsection{World Wide Access}

Instead of using books and materials, the students can have access to the internet by using cloud computing. Learning in cloud also makes cheap access to terminals, because applications are running in the cloud servers. That will significantly benefit the developing countries a lot.

\subsubsection{Collaborative Interaction}

Learners can collaboratively build knowledge through convenient interactions anywhere in the cloud. They can track their learning improvements and results. Knowledge can be fully utilized through interaction.

\subsubsection{Students Centered}

Learning in cloud is people-oriented. It encounters specific requirements of the learners. Students in the Cloud can select appropriate resources and record individual outcomes and specific process.

\section{Literature Review}

AnthonyT.Velte et al. [1] discussed about the various stages of services offered by cloud computing. The memory, software, network, operating systems and servers can be managed using HaaS (Hardware as a Service). Users can deploy applications which are developed with the help of programming languages and tools on the cloud using PaaS (Platform as a Service). Applications on the cloud infrastructure are made available via a third-party over the internet using SaaS (Software as a Service). Nabeela Altrabsheh et al. [16] discussed the means of gathering feedback through social media like Twitter and how sentiment analysis is used on the educational data to improve teaching. Palaniappan stated that cloud computing in academic atmosphere will be benefitted by every student and faculty where lots of teamwork and protection of data is needed in academic. The ability of scaling and elasticity of cloud computing is accurate for academic environment [17]. Raed Alsufyani et al. clarified cloud computing to highlight its significance, taxonomies and explanations for adoption in university. They also explained about the cloud computing frameworks, and aspects for deploying cloud computing in education [18]. Elizabeth Muli, James Kimutai analyzed the strength, weaknesses, opportunities and threats in cloud computing. The results exhibited that maximum universities deployed SaaS for knowledge administration and learner e-mails. They concluded that cloud computing can travel a long way in improving teaching and learning, however there are insecurity views among users [3]. Accordingly, Manjeet and Chitranjan in [11] highlighted the concept, services and benefits provided by Cloud computing for e-learning and also focused on cloud computing initiatives. Sudeepa and Guruprasad in [20] discussed about the various resource allocation techniques in cloud computing. Due to the increasing demands of the end users for resources and services, it becomes difficult to allocate the resources correctly to the demands of users in order to satisfy the user requests. 
In this regard, Ibrahim Arpaci in [7] attempted to construct a considerably enhanced research framework in order to detect features which affect outlooks of students towards the usage of mobile cloud storing facilities. Kamisli Ozturk.Z et al. [9] described mining in social media and examined sentiment for distance education students. Using data mining techniques, these tweets were analyzed and results were visualized. Wen-Lung Shiau Patrick Y.K. Chau illustrated that the students in colleges and universities afford cloud computing technologies as new facility to fascinate. Therefore, recognizing Behavioral Intention of students towards the usage of cloud computing classrooms is vibrant [23].

Garima Rastogi et al. [5] analyzed the features which affect cloud adoption services in India. The willingness to accept cloud services inspires the real use of cloud computing services positively. In addition, perceived risks have also been studied. Maroof Naieem Qadri, SMK Quadri demonstrated the cloud computing basic architecture and the usage of cloud have to be done in an extraordinary potential to offer cost effective, secure, high reliable, easy to manage, elastic and powerful resources over the internet [12]. Mark Stieninger et al. analyzed the compatibility factors, relative advantage, trust \& security, a lesser level of difficulty leads to a more optimistic approach towards adoption of cloud [13]. Fitore Kostanica et al. [4] examined the effect of the most important factors that impacts purpose to adopt Cloud computing by Kosovo students. The analysis fits context and was further extended by four factors. Factors used for this study are dependent variable. Ban Salman Shukur et al. [2] proposed a framework model of cloud computing in Higher Education Institutes in Developing Countries. A revised hybrid cloud model is recommended for supporting the framework model.

In this regard, Hoong-Cheng Soong et al. discussed about the sentimentality classification. A general framework for text sentiment analysis which uses the approach of machine learning was proposed in [6]. Jewan Singh, Vibhakar Mansotra proposed a theoretical model outline which describes part of technological, organizational and environmental aspects on acceptance of cloud services in school educational process of India. Results of study specified that technology and environmental backgrounds show positive and important part in the choice of adhering cloud computing in school education sectors [8]. Muhammad and Riyaz reviewed what set-up cloud will provide in educational field, particularly in the institutions where the practice of computers are more demanding and what steps can be taken to rise aids of collective presentations for learners and faculties, and how the system can be developed to work in any type of cloud environments [15]. Lillian-Yee-Kiaw Wang et al. [10] observed that enjoyment and computer self-efficacy considerably affect the students willingness to remain using cloud e-learning application.

Tanweer and Mohamed proposed an approach for developing smart classrooms by integrating blockchain and Internet of Things technologies in the educational system. They have illustrated that the higher education institutions are introducing courses related to blockchain due to the technological advancements. This could help the institutions to minimize the costs and allow distributes services. They have concluded that to provide communication security for transmitting large amount of data in a heterogeneous environment this framework is appropriate [21]. Thamer Al-Rousan and Hasan Abu Al Ese [22] offered to establish the practice of private cloud computing in education in an actual condition. Results illustrated that resources of cloud delivered suppleness for learners and faculties with comfort of access, permitting more active, efficient association within and between the research groups. Yousef A. M. Qasem et al. [24] included an outline of the fundamental features of the developing field in terms of inspiration and obstacles of adhering cloud computing in higher educational institutions, features that encourage acceptance of cloud computing at the single and administrative levels. Mohammad Kayali et al. tested the UTAUT which investigated the effect of individual factors on the behavioral intention to adopt cloud based e-learning [14]. Rui Song et al. [19] proposed an efficient system established on hybrid multi-channel framework to categorize and extract image features namely actions, expressions of students, audio features like rate of speech and pauses in video assignments.

\section{Method of Study and Research Questions}

The objective of this study is to assess student's perceptions in using cloud computing technologies for education. The following research questions were considered.

1. What are the factors influencing student's perceptions and adoption rate of cloud learning environment in higher education sectors?

2. What are the powerful solutions provided by cloud applications to students?

3. What are the benefits of cloud computing services to students, teachers and various deployment models in cloud computing?

4. Usage of various cloud platforms by students and what are the frequently used cloud applications by them?

5. How to migrate to cloud in higher education institutions?

\subsection{Survey Participants}

The targeted respondents were a cluster of 108 students in one of the private University in Chengalpattu, India. 
Their registrations in various courses irrespective of age, gender and year of course were considered for the online survey. Online survey is used to gather the data, which reflects outlook of students. Survey allows data gathering through framing of questions which reflects perceptions, ideas and activities of a small group of students. The respondents are from both computer science and non IT background. The non IT students also possess the basic knowledge of computers.

\subsection{Data Collection and Analysis}

In this study, the instrument which was used to collect data is questionnaire. It was used to explain the student's perceptions on the use of cloud technologies. The first section of the questionnaire describes the demographic information of the students and consists of gender, age, course, background. Table 1 depicts demographic details of the students. Among total number of respondents, $66.67 \%$ $(n=72)$ were males and $33.33 \%(n=36)$ were females. The average age of the students was 20 years old. Responses from respondents as illustrated in Figure 2 reveals that all the students were from a combination of IT and non-IT background, pursuing various specializations, like B.Com
(General), B.Com (ISM), B.Sc. Agriculture and M.Sc.IT. The largest group of students participated in the study were students of third year B.Com (General) full time followed by second year B.Com (ISM) full time. In third place were students of first year M.Sc.IT full time. The smallest group of students were the first year B.Sc. Agriculture full time. The responses from the survey were exported into Microsoft Excel for statistical analysis.

Table 1. Demographic details of the respondents

\begin{tabular}{|c|c|c|c|}
\hline Variable & Label & $\begin{array}{c}\text { Frequency } \\
(\mathrm{n}=108)\end{array}$ & Percentage \\
\hline \multirow{3}{*}{ Gender } & Male & 72 & $66.67 \%$ \\
\cline { 2 - 4 } & Female & 36 & $33.33 \%$ \\
\hline \multirow{3}{*}{ Age Range } & $17-19$ years old & 41 & $37.96 \%$ \\
\cline { 2 - 4 } & 20 years old & 34 & $31.48 \%$ \\
\cline { 2 - 4 } & $21-45$ years old & 33 & $30.56 \%$ \\
\hline \multirow{3}{*}{ Course } & $\begin{array}{c}\text { Under Graduate } \\
\text { Degree }\end{array}$ & 87 & $80.56 \%$ \\
\cline { 2 - 4 } & Master Degree & 21 & $19.44 \%$ \\
\hline \multirow{2}{*}{ Background } & Village & 34 & $31.48 \%$ \\
\cline { 2 - 4 } & City & 74 & $68.52 \%$ \\
\hline
\end{tabular}

Percentage of students participated in the survey according to their course and year

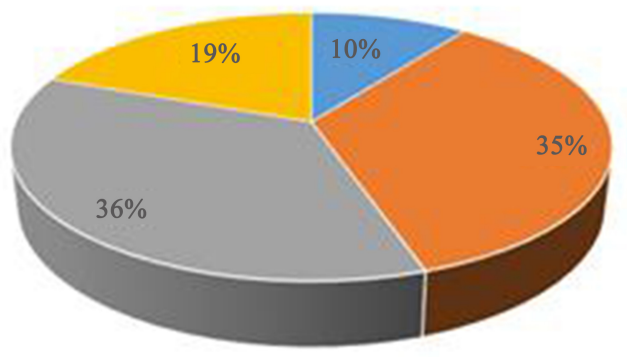

- I year B.Sc Agriculture = II year B.Com (ISM)

- III year B.Com (General) I year M.Sc.IT

Figure 2. The structure of students participated in the survey according to their course and year 
The second section includes specific questions about the usability of cloud computing applications for learning by the students. The Likert scale was used to rate the responses on a scale of 1 to 5 as shown below. Table 2 shows the range of mean score for interest of students towards cloud applications usage.

Table 2. Interpretation of mean score

\begin{tabular}{|c|c|}
\hline Score & Interpretation \\
\hline (0.01 to 1.00$)$ & Very Rarely (<10\% of time) \\
\hline (1.01 to 2.00$)$ & Rarely (10\% to $30 \%$ of time) \\
\hline (2.01 to 3.00$)$ & Occasionally (30\% to $50 \%$ of time) \\
\hline (3.01 to 4.00$)$ & Sometimes ( $50 \%$ to $70 \%$ of time) \\
\hline (4.01 to 5.00$)$ & Frequently (70\% to $100 \%$ of time) \\
\hline
\end{tabular}

Likert scale offers high representatives of the whole people and is of little price. In this study the questions are analyzed using quantitative methods and it involves 2-D column bar chart for representation. The collected data were analyzed to investigate the intention of the students to use cloud applications and services in learning process.

\section{Factors Influencing Student's Preference of Cloud in Educational Context}

The cloud computing provides a prime doorway to education associated amenities and information. This allows the educational organizations to provide services by reducing the carbon emissions.

\subsection{Keeping Student's Data Safe}

The trusted cloud service provider's offers secured features to higher education institutions to guard the data of students.

\subsection{Cloud Based Teamwork}

Students find difficulties when collaborating with others. Cloud built digital platform lets teachers to teach the syllabus and deliver assessments to each student established on their progress. The cloud creates a strong foundation for students to have an easy access to resources across various platforms and develop their collaboration skills. For example, when students work on projects, they can collaborate with other students, however their teachers can provide online feedback, this allows teachers to complete grading a class assignment in fewer hours. It permits for instant response and valuation processes, which profits both learners and educators simultaneously.

\subsection{Flattening Playing Field}

Colleges in rural areas can't afford licensing software for each student. Through cloud, technologies students can have limitless experience to standard tools of the industry. Cloud technology is a dominant tool which can be used by colleges to increase the outcome of students, keep the data of student's safe, expand finances further, and save the time of educator. Utilizing the services of cloud-based learning, more efforts have to be taken to widen and extend its implementation.

\subsection{Time \& Ease}

Time is the major constraint for educators. Teachers can concentrate more on their subjects when they use cloud infrastructure. Cloud holds all information, so educators will not be stretched to deal with the hindrance of misplaced resources and assignments. They can give their feedbacks and provide grade from their device. They don't want to carry home stacks of papers and notebooks. Cloud retains all the information, even if an instructor's laptop fails, all the information need not be reconstructed.

\subsection{Hasten Advancement in Classroom or Lab}

Kindle novel ideas through your own research and support the students that you teach. Students can be given greater access to latest technologies namely G Suite. Researchers, effortlessly measure your projects with remarkable speeds, deep data storage and intensive processing power.

\section{Powerful Solutions provided by Cloud Education Applications to Students}

Education based applications provides convenience by helping the students to achieve more goals in less time. Still some of the teachers follow the traditional approach for teaching. The teacher-centered learning demotivates the students to learn. Cloud learning environment provides more powerful solution which enhances smart learning environment in terms of learning methods and materials to attract students to learn (Figure 3). The implementation of cloud learning environment aims to enhance learning experience of students.

Cloud learning environment is based on the student-centered learning. The planned curriculums, modules, videos and assignments can be integrated into cloud environment to enhance skills and fun learning environment. In cloud computing resource allocation allocates and schedules the resources efficiently with high resource utilization and low cost. This study emphases on the learning habit of cloud amenities, of the students and the way it benefits to higher educational institutions. It gives enhanced accepting of concept of cloud applications, services in higher education sectors. Students' mobile device acts as a computing resource using which they can access their learning materials. Mobile learning services support teaching and training for large group of students. 


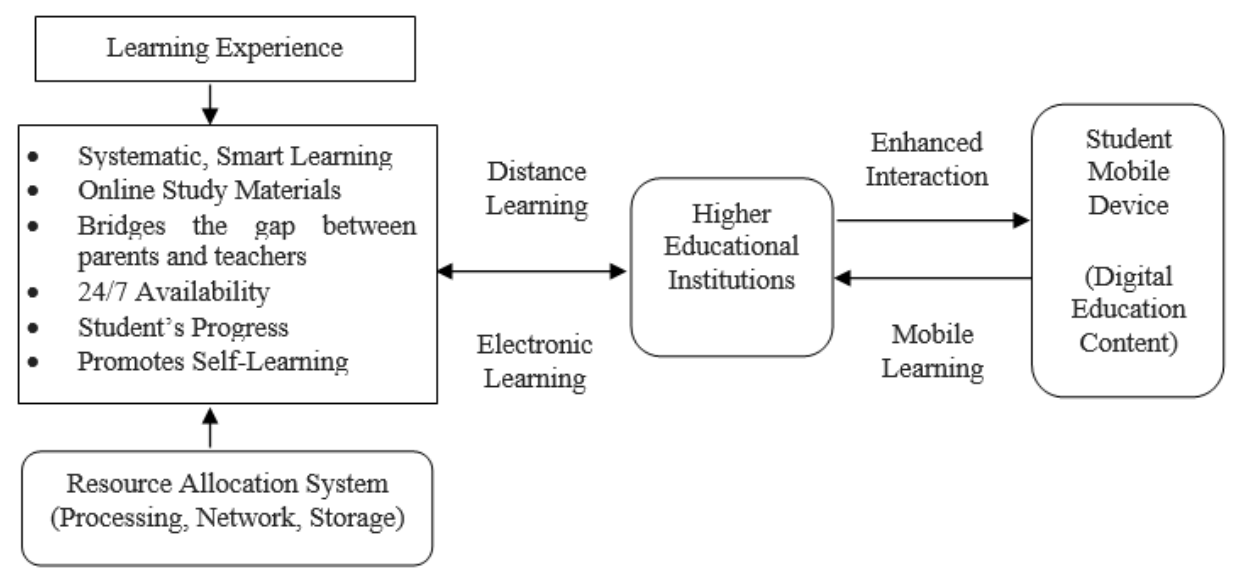

Figure 3. Solutions provided by education applications to students

\section{Advantages of Cloud Services to Higher Education Institutions}

Cloud computing offers Hardware (HaaS), Platform (PaaS), Software (SaaS) to educational organizations. The advantages of using these amenities:

- Quick distribution of information technology facilities, resources

- Lesser hardware, functioning charge

- $\quad$ Efficient computing background

- $\quad$ Cost savings with built-in cloud storage efficiencies.

\subsection{Analysis of Cloud Computing in Teaching}

In earlier days, students work individually struggle for completing their course works and projects since only 1 person can work on 1file. But nowadays, collaborative work is increased. All learners can work on similar file using their tablet, cell phone and lots of other equipment of university at the same course of time. They need not to be in same location.

Cloud computing is widely used by undergraduate and postgraduate students. But it is not frequently used by the instructors. They have been following the traditional method of teaching for many years, so they have to shift the system of teaching their classes. When we want to implement cloud computing in classroom, the faculties should take a step forward because the student's needs and the approach of learning are entirely different in the generation of current technology. Sufficient training towards the usage of latest cloud technologies has to be given to the faculties, which intends the students to improve their learning experience.

\subsection{Profits of Cloud Computing to Learners and Educators}

"Using cloud-based learning, teachers are improvising on teaching methodologies by integrating modern technologies such as blended learning and collaborative learning, thus creating an effective learning environment for students". The higher education sectors can have the following profits:

1. Novel advanced techniques for teaching and learning.

2. The class materials can be accessed fastly.

3. Easy interaction among lecturers and learners, they need not present in lecture hall.

4. Advancement of E-learning.

5. Motivation of a collaborative learning background between learners employed together.

6. Improvement of team based job permitting learners to share course work materials, papers, software, etc.

7. Enhanced communication among learners and lecturers during the class. When lecturers ask queries students can participate by using online interactive software. By using the student's real time answers the instructors can focus on their weakness.

8. When the learners work on assignments, they can receive more feedbacks in real time.

\section{Types of Cloud Computing Deployment Models for Education}

\subsection{Public Cloud}

In this model, administration, maintenance of the pool of resources and the entire cloud infrastructure are done by the third parties. The higher education institutions can adopt the application and services by having an agreement with trusted cloud service providers.

\subsection{Private Cloud}

This model is best for higher education institutions to develop their own dedicated cloud computing environments rather than buying the applications services from third-party providers. Private clouds are more secured and they provide consistent services to researchers, students, faculties. 


\subsection{Hybrid Cloud}

This model integrates the features of both public, private clouds services. In this infrastructure, some part of the organization's resources are partially hosted within the organization and the rest are hosted externally in a public cloud.

Table 3. Cloud Computing Deployment Models in Education

\begin{tabular}{|c|c|c|c|c|}
\hline Deployment Model & Ownership & Location & Access Right & $\begin{array}{c}\text { Cloud Customization } \\
\text { and Control }\end{array}$ \\
\hline Public & Cloud Providers & $\begin{array}{c}\text { Outside the Higher Education } \\
\text { Institutions }\end{array}$ & By subscription & No \\
\hline Private & $\begin{array}{c}\text { Higher Education } \\
\text { Institutions }\end{array}$ & $\begin{array}{c}\text { Within the Higher Education } \\
\text { Institutions }\end{array}$ & $\begin{array}{c}\text { Limited to students, } \\
\text { faculties, staff }\end{array}$ & Yes \\
\hline Hybrid & $\begin{array}{c}\text { Both Higher Education } \\
\text { Institutions and Cloud } \\
\text { Providers }\end{array}$ & $\begin{array}{c}\text { Within or outside the Higher } \\
\text { Education Institutions }\end{array}$ & On both & $\begin{array}{c}\text { Depends on Higher } \\
\text { Education Institutions }\end{array}$ \\
\hline
\end{tabular}

\section{Deployment of Software-as-a-Service}

Nowadays SaaS has become trendy. When higher education sectors move towards SaaS platform, the number of servers can be reduced. SaaS is a striking contribution to higher education sectors.

\subsection{Running Automatic Upgrades, Relocations and Patches}

Nowadays, many of the activities taking place in the cloud and changes are automatically received from software vendors. Many academic sectors started to move towards Microsoft Office 365 which helps faculties, administrators, and learners to use the cloud based options provided by the vendors to access the programs.

\subsection{Strengthening Innovative Levels of Student Collaboration}

Cloud computing provides the most tech-savvy digital technologies. The faculties can create new coaching styles through incorporating recent technologies like blended learning and collaborative learning, hence generating an efficient educative location for learners.

\subsection{Improving Reachability}

Cloud plays a massive role in delivering education by using streaming on the web. Cloud can be used as an innovative platform for delivering classroom lectures; enabling seamless collaboration between students and teachers irrespective of their geographical location.

\subsection{Streamlining Administrative Work}

Along with imparting education, teachers are also responsible for various administrative activities. Cloud smoothens the administrative responsibilities which helps the teachers to focus on the core activity of teaching. E.g. CRM systems can help to maintain large volumes of data such as student's details, academic performance and growth. 


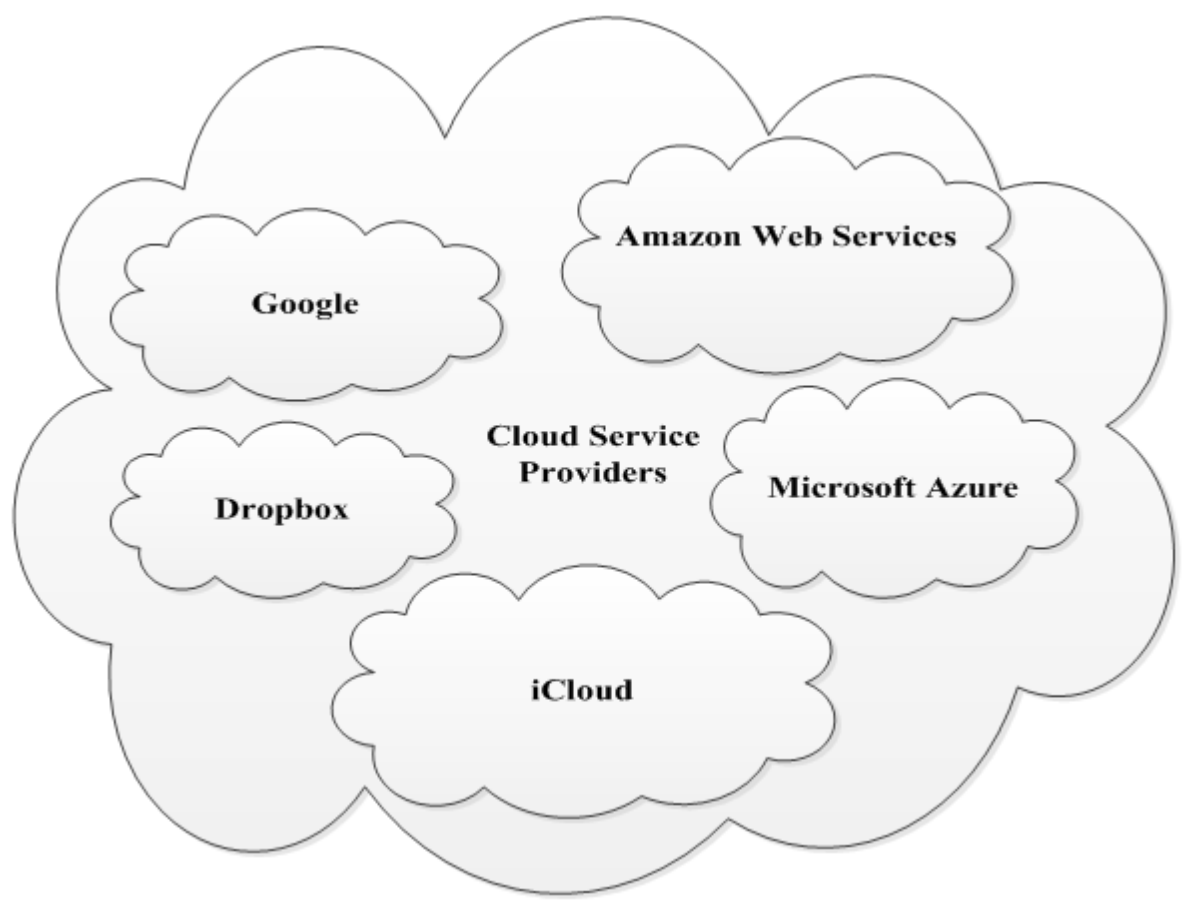

Figure 4. Cloud Service Providers

\section{Top Cloud Computing Providers}

Using cloud computing, everyone using World Wide Web enjoys flexible on-demand rights to shared group of resources. It reduces the pressure on education institutions in investing and maintaining costly hardware and software. It has become the new era of computing. There are various cloud service providers. The top cloud computing platforms are Google, Dropbox, Apple, Microsoft and Amazon (Figure 4) and so on.

\section{Usage of Various Cloud Platforms by Students}

\subsection{Cloud Data Storage and Backup Applications}

Table 4 shows student's usage of various cloud data storage and backup applications. Microsoft OneDrive is a powerful cloud storage service that integrates effortlessly with Microsoft 365's native applications. Well-designed and efficient apps are available across most mobile and web-enabled devices, making digital collaboration simple. A free file storing application is Google Drive. It permits educators to stock and access documents located in the cloud. This app is esteemed as one of the most resourceful cloud storage services because of its ability to synchronize stored files across mobile devices, PCs. Amazon Cloud Drive is proposed to store photos and files in one secured location. Once the files are uploaded, they can be accessed from any device. The iCloud, provided by Apple, is a cloud-based storage suite system that allows Apple device users to securely store documents, media files, and application data on dedicated Apple servers. As files are put on each iOS, iCloud automatically synchronizes all the data amidst the range of a user's Apple devices that are connected to the Internet.

Dropbox is a cloud storage service that allows educators to store practically any kind of file on cloud servers remotely with the capability to share these files across all PCs or mobile devices. MediaFire offers file presenting, cloud storing, and synchronizing service. It provides a convenient solution for handling online digital material. Megaupload Ltd provides online services associated to file storing and viewing. Google Calendar is a free time management and SaaS app that allows users to create and modify calendars in order to keep track of their personal and professional events. Gmail is a free web-based messaging system developed by Google.

Table 4 clearly depicts that Gmail has the highest mean score. It is most popularly used application by the students. This App can be accessed through any web browser irrespective of the user's geographic location as long as an Internet connection is present. Students can create a google account, and they can access their Gmail and many other Google apps. The least mean score is Microsoft One Drive. Figure 5 shows the chart illustrating cloud data storage and backup applications usage by the students of the University. 
Table 4. Usage of Cloud Data Storage and Backup Applications by Students

\begin{tabular}{|c|c|c|c|c|c|c|c|}
\hline Cloud Computing Applications & $\begin{array}{c}\text { Very } \\
\text { Rarely }\end{array}$ & Rarely & Occasionally & Sometimes & Frequently & $\begin{array}{c}\text { Mean } \\
\text { Score }\end{array}$ & Rank \\
\hline Microsoft OneDrive & 82 & 9 & 5 & 10 & 2 & 1.53 & 8 \\
\hline Google Drive & 21 & 18 & 14 & 16 & 39 & 3.31 & 2 \\
\hline Amazon Cloud Drive & 69 & 8 & 11 & 8 & 12 & 1.94 & 5 \\
\hline Apple icloud & 78 & 13 & 3 & 4 & 10 & 1.66 & 7 \\
\hline Dropbox & 71 & 10 & 14 & 6 & 7 & 1.78 & 6 \\
\hline $\begin{array}{c}\text { Online file storage using } \\
\text { MediaFire, Megaupload }\end{array}$ & 57 & 10 & 18 & 5 & 18 & 2.23 & 4 \\
\hline Google Calendar & 37 & 24 & 6 & 14 & 27 & 2.72 & 3 \\
\hline Gmail & 12 & 27 & 7 & 6 & 56 & 3.62 & 1 \\
\hline
\end{tabular}

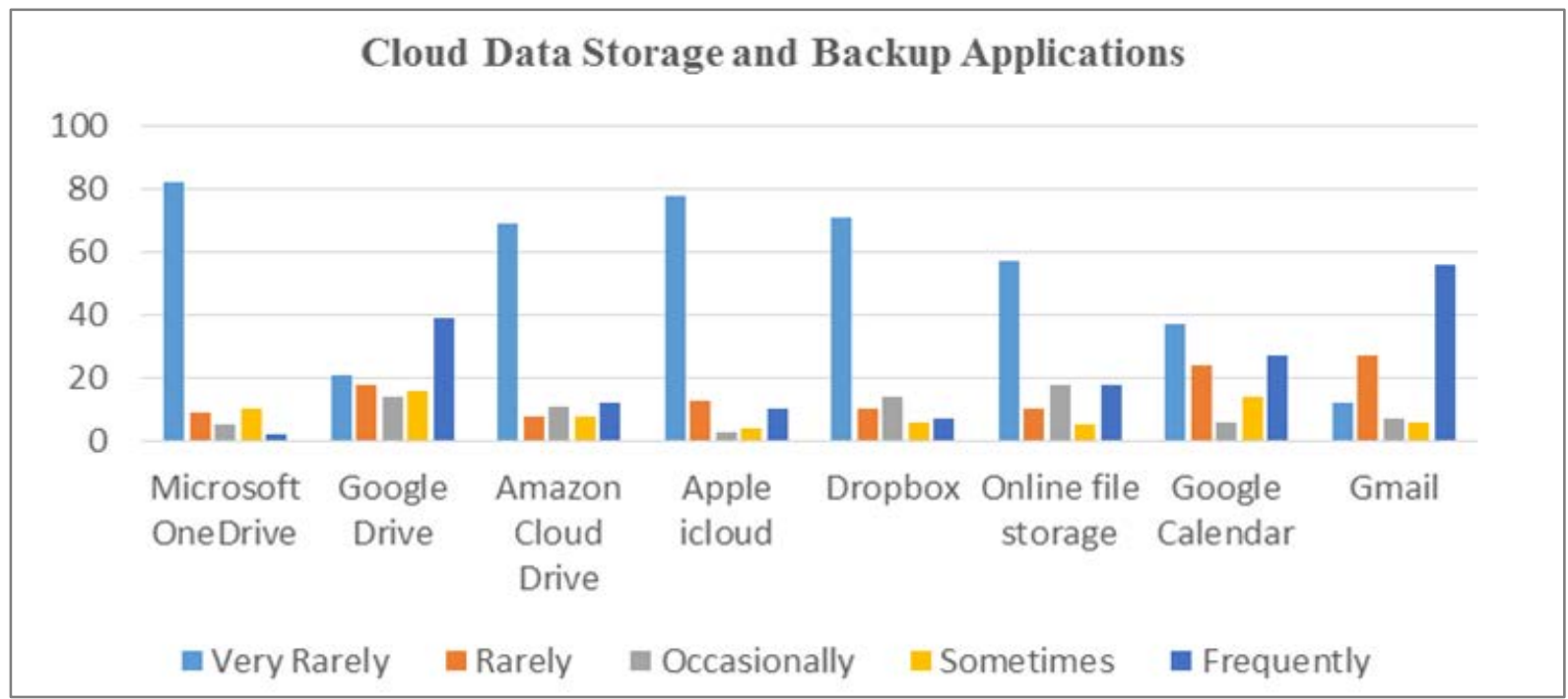

Figure 5. Chart illustrating cloud data storage and backup applications usage by students

\subsection{Commonly Used Cloud Computing Applications}

Table 5 depicts the commonly used cloud applications by respondents. Microsoft Office 365 can be accessed by the educators using devices like smartphones, iPads and laptops. Learners and educators at authorized institutions can sign up for free. It includes Word, Excel, PowerPoint, OneNote, and additional classroom tools. Students can upload and download photos, videos in the Flickr app. It allows them to organize images into albums. When students need to create a presentation they can use Sliderocket, a free online application. Another online word processing and document editing application is Writeboard. It has an exclusive feature that many students can access the same file using this application, update that file and save the file after editing, but the file will have different versions. The findings obtained from Table 5 , show that the highest mean score for the items is the usage of photo editing software like Picnik, Pixlr by the students. Image cropping, resizing, degree based rotation and special effects are few features provided by this online software. The least mean value for the items is Cloud Antivirus and Adobe Creative Cloud. Cloud Antivirus application provides functionality to detect and fix a system infected with malware and other computer viruses. Adobe Creative Cloud offers a suite of apps which students use for video editing, web development, photography and graphic design. Figure 6 shows the chart illustrating commonly used cloud computing applications by students of the university 
Table 5. Commonly Used Cloud Computing Applications by Students

\begin{tabular}{|c|c|c|c|c|c|c|c|}
\hline $\begin{array}{c}\text { Cloud Computing } \\
\text { Applications }\end{array}$ & Very Rarely & Rarely & Occasionally & Sometimes & Frequently & $\begin{array}{c}\text { Mean } \\
\text { Score }\end{array}$ & Rank \\
\hline Microsoft Office 365 & 72 & 8 & 8 & 14 & 6 & 1.83 & 3 \\
\hline $\begin{array}{c}\text { Photo Editing Software } \\
\text { Picnik, Pixlr }\end{array}$ & 49 & 12 & 10 & 18 & 19 & 2.50 & 1 \\
\hline Creating Image Album & 63 & 11 & 13 & 10 & 11 & 2.03 & 2 \\
\hline Sliderocket, Writeboard & 87 & 4 & 6 & 5 & 6 & 1.51 & 6 \\
\hline Cloud Antivirus & 74 & 9 & 7 & 10 & 8 & 1.79 & 4 \\
\hline Adobe Creative Cloud & 71 & 13 & 6 & 12 & 6 & 1.79 & 4 \\
\hline
\end{tabular}

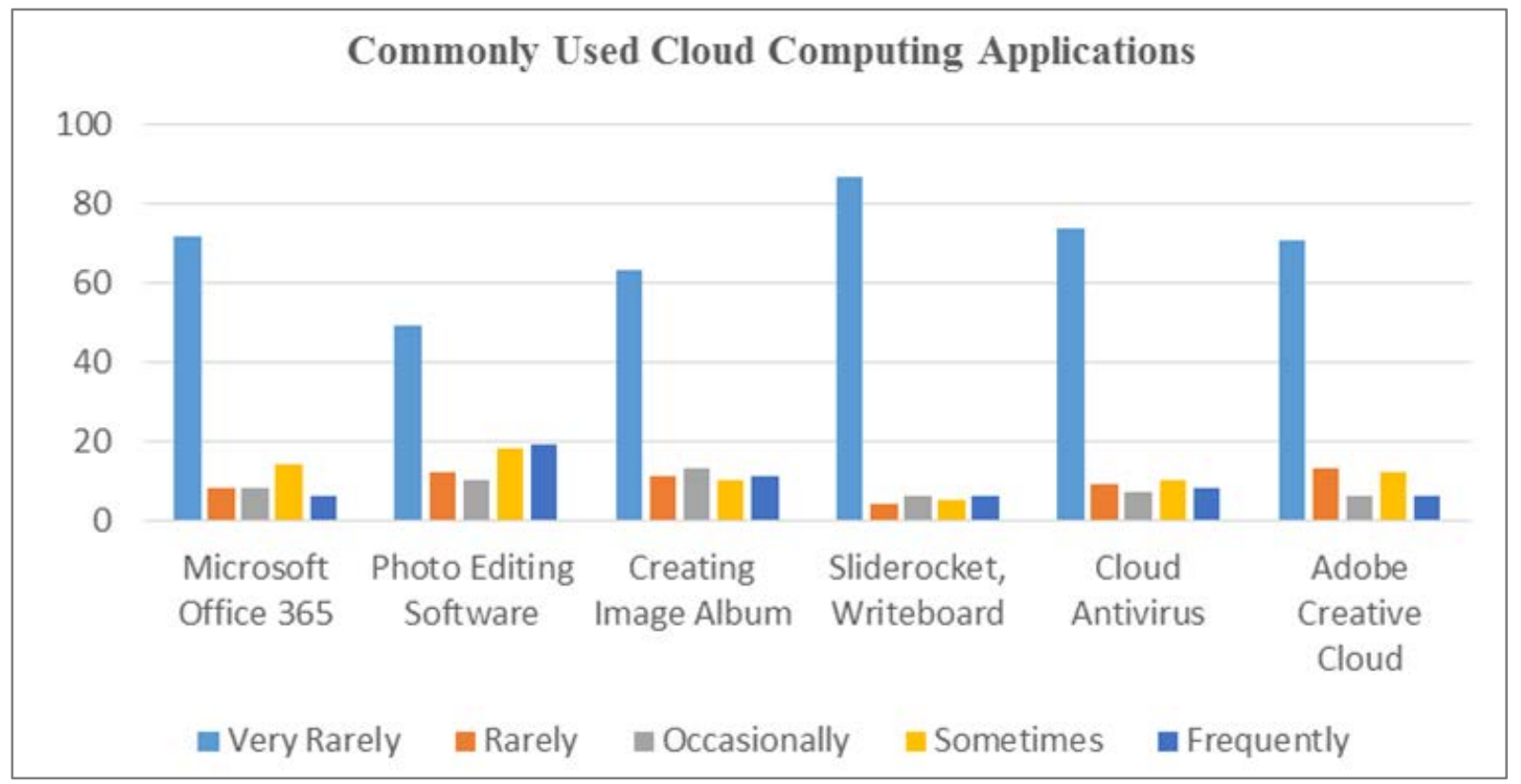

Figure 6. Chart illustrating commonly used cloud computing applications usage by students

\subsection{Cloud Map Applications}

Maps help to explore the real-world insights and immersive location experiences. Table 6 shows the usage of cloud leading map platforms by respondents. Over the last decade, these free online applications helped millions of users by displaying direction, paths and helped people get to their destinations. Maps offer resources to help educators and learners discover, generate and cooperate with mapping tools. Students can use cloud map applications to get walking and biking directions, trip planning using public transportation, relate neighborhoods and communities across the world, and understand traffic patterns. Table 6 shows that the highest mean score is Google Maps. The least used map application is MapQuest. Figure 7 depicts the chart illustrating cloud map applications usage by the students of the University.

\subsection{Social Media Related Applications}

The social networks continue to advance in our everyday life. Table 7 depicts the usage of social media related applications by the respondents. The highest mean score for the items is WhatsApp. A particular group can be created in WhatsApp for each department. Instructors can share their learning materials through group messages. On the other hand the least mean score is Twitter. The digital tool plays a vital part in education institutions in correlation with traditional methods. Communication is the intended core of social media. It provides excessive opportunities for the higher education sectors to link, share and study. Figure 8 depicts the chart illustrating social media related applications usage by students. 
Table 6. Usage of Cloud Map Applications by Students

\begin{tabular}{|c|c|c|c|c|c|c|c|}
\hline $\begin{array}{c}\text { Cloud Computing } \\
\text { Applications }\end{array}$ & $\begin{array}{c}\text { Very } \\
\text { Rarely }\end{array}$ & Rarely & Occasionally & Sometimes & Frequently & $\begin{array}{c}\text { Mean } \\
\text { Score }\end{array}$ & Rank \\
\hline Google Maps & 16 & 22 & 6 & 14 & 50 & 3.56 & 1 \\
\hline Yahoo Maps & 79 & 8 & 5 & 8 & 8 & 1.69 & 2 \\
\hline MapQuest & 85 & 7 & 6 & 4 & 6 & 1.51 & 3 \\
\hline
\end{tabular}

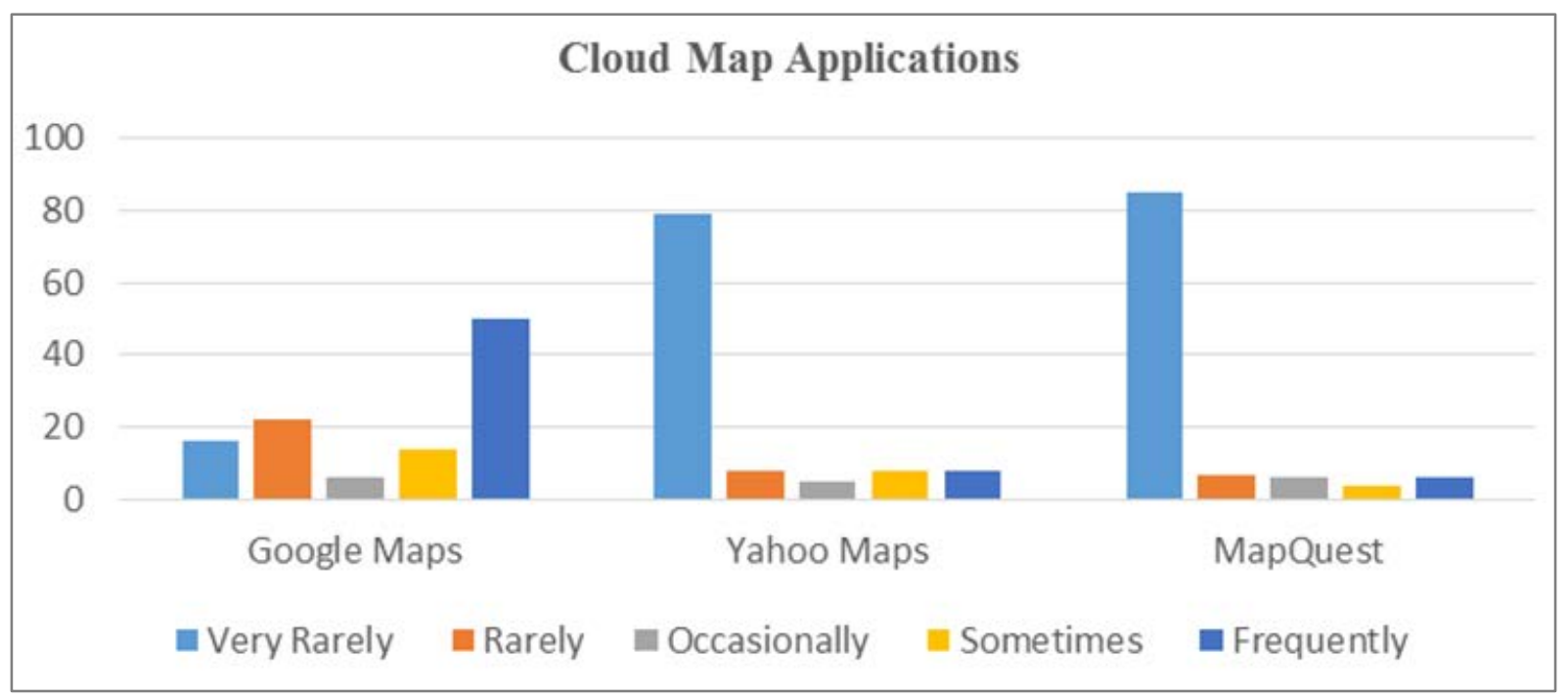

Figure 7. Chart illustrating cloud map applications usage by students

Table 7. Usage of Social Media Related Applications by Students

\begin{tabular}{|c|c|c|c|c|c|c|c|}
\hline $\begin{array}{c}\text { Cloud Computing } \\
\text { Applications }\end{array}$ & $\begin{array}{c}\text { Very } \\
\text { Rarely }\end{array}$ & Rarely & Occasionally & Sometimes & Frequently & $\begin{array}{c}\text { Mean } \\
\text { Score }\end{array}$ & Rank \\
\hline WhatsApp & 11 & 25 & 4 & 5 & 63 & 3.78 & 1 \\
\hline Twitter & 63 & 14 & 6 & 9 & 16 & 2.08 & 3 \\
\hline You Tube & 16 & 22 & 0 & 5 & 65 & 3.75 & 2 \\
\hline
\end{tabular}

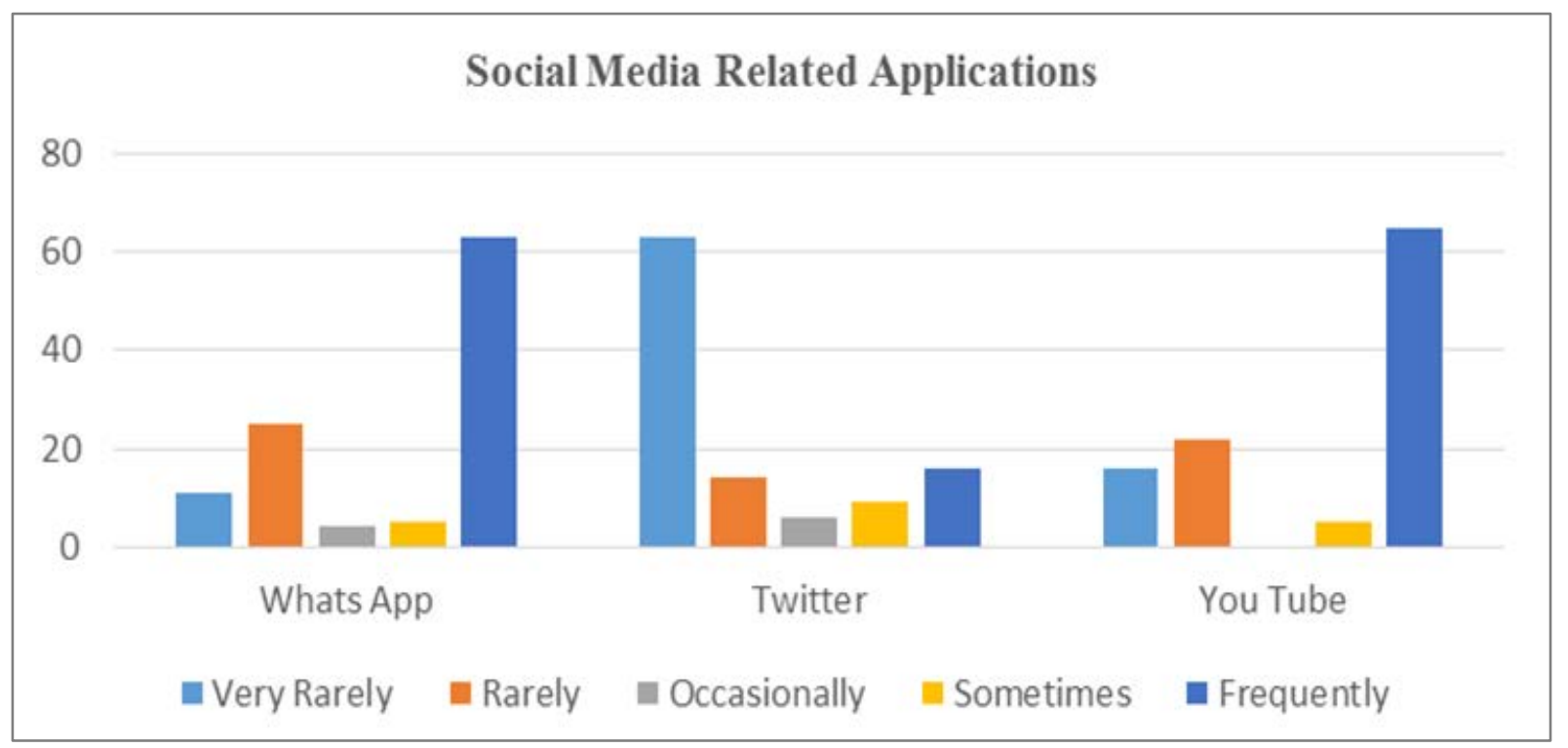

Figure 8. Chart illustrating social media related applications usage by students 


\section{Findings and Discussions}

This study aims to investigate the student's continuous intension in using the cloud computing services. Both under graduate and post graduate students participated in the survey. Microsoft SQL Server was used to find the frequently used cloud applications by the students of the University (Figure 9). Table 8 clearly shows that from among the notably powerful cloud applications the student's intension is more towards the usage of social media related applications for learning. $60 \%$ of students use You Tube for watching video lectures. 58\% of students use Whatsapp for sharing their learning materials. 52\% of the students use Gmail for saving and sharing their files. On the other hand very rarely used cloud services are Adobe Creative Cloud, Sliderocket \& Writeboard, MapQuest, Office 365 followed by One Drive. Figure 10 clearly depicts the chart illustrating percentage of students using each cloud platform frequently. Cloud makes it possible for the students to store and share the learning materials, e-books and journals anywhere and anytime when they are connected to internet.

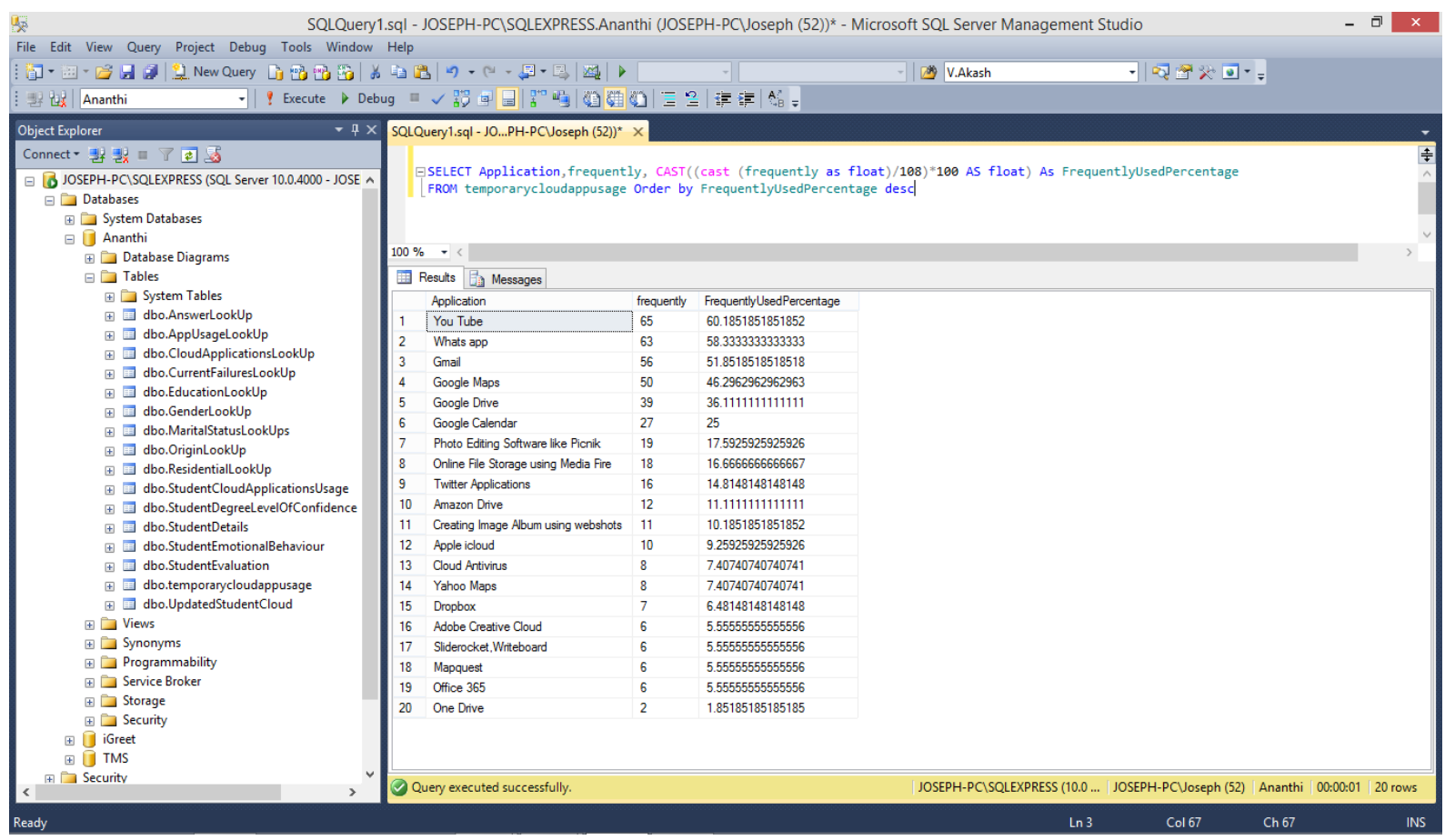

Figure 9. Frequently used percentage of cloud platform by students of the University using Microsoft SQL Server 
Table 8. Percentage of Frequently Used Cloud Applications by Students

\begin{tabular}{|c|c|c|}
\hline Cloud Computing Applications & $\begin{array}{l}\text { No. of students using the cloud } \\
\text { applications frequently }\end{array}$ & $\begin{array}{c}\% \text { of students who use each cloud } \\
\text { platform frequently }\end{array}$ \\
\hline You Tube & 65 & $60.19 \%$ \\
\hline WhatsApp & 63 & $58.33 \%$ \\
\hline Gmail & 56 & $51.85 \%$ \\
\hline Google Maps & 50 & $46.30 \%$ \\
\hline Google Drive & 39 & $36.11 \%$ \\
\hline Google Calendar & 27 & $25.00 \%$ \\
\hline Photo Editing Software & 19 & $17.59 \%$ \\
\hline Online File Storage & 18 & $16.67 \%$ \\
\hline Twitter Applications & 16 & $14.81 \%$ \\
\hline Amazon Drive & 12 & $11.11 \%$ \\
\hline Creating Image Album & 11 & $10.19 \%$ \\
\hline Apple icloud & 10 & $9.26 \%$ \\
\hline Cloud Antivirus & 8 & $7.41 \%$ \\
\hline Yahoo Maps & 8 & $7.41 \%$ \\
\hline Dropbox & 7 & $6.48 \%$ \\
\hline Adobe Creative Cloud & 6 & $5.56 \%$ \\
\hline Sliderocket,Writeboard & 6 & $5.56 \%$ \\
\hline MapQuest & 6 & $5.56 \%$ \\
\hline Office 365 & 6 & $5.56 \%$ \\
\hline One Drive & 2 & $1.85 \%$ \\
\hline
\end{tabular}

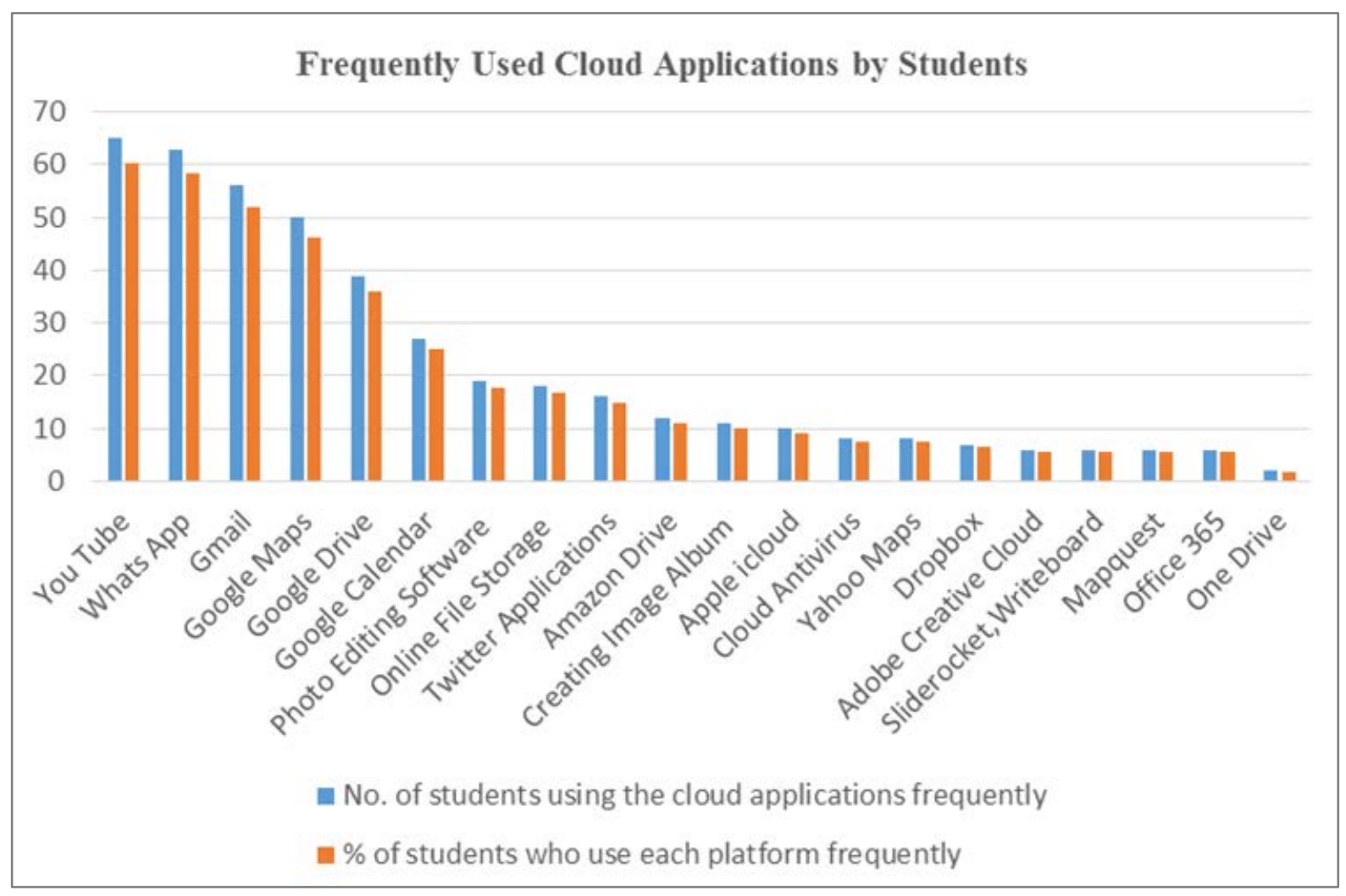

Figure 10. Chart illustrating percentage of students using each cloud platform frequently 


\section{Migration to Cloud Computing in Higher Education Institutions}

First we have to decide what data to be sent to the cloud and what data not to be send to the cloud. We have to decide the important applications to be maintained on cloud. One institution will differ from another institution, then we will not migrate the most important applications to cloud. When we make a decision to migrate to cloud, make certain the applications we are going to use won't take too many system properties. When application we wish to use on cloud demands greater enactment, less potential make certain that cloud service provider we have selected satisfy our needs.

\section{Establishing Relationship between Cloud Computing and Higher Education}

To minimize capital expenditure for providing information technology infrastructure the commencement of cloud computing technology, is believed to make feasible improvements for higher education system. The relationship between cloud computing and higher education can be described in three ways:

\section{Lower Cost}

In earlier days most of the technologies were very costly to implement. But now they are web based and free to everyone. To enrich technology-enabled education and to reduce the budget impact the higher education system should take advantage of cloud computing technologies.

\section{Growth of Content}

Traditionally the content creation was very personal and has short life span. Nowadays, publishing text, photos, art and opinion is open to large audience. With the new age of Information Technology the higher education systems can create the content that can last for many years.

\section{Integration}

By integrating cloud and Internet of Things (IOT) into university extensive creativities is a vital step in developing the interaction of the higher education students and improving their overall experience. By integrating cloud and Artificial Intelligence into higher education allows the faculties to identify the learning areas where the students are at risk and they can devote more time in such areas, thus developing the higher education.

\section{Developing Higher Education in Information Technology Age}

In this era of Information Technology, the higher education is influenced by the technologies of cloud computing. Due to the present economic disaster and rising requirements, it can be considered an effective substitute to the educational sectors which are struggling in providing essential information, quality education, technology, development and research activities. Higher education institutions can consume a highly scalable Information Technology infrastructure by using cloud computing and the support arrangement is key technology like virtualization, where the resources can be allocated dynamically and shared. They can use cloud for various purposes like academic, administrative and community services. The institutions can have the readily accessible online applications over using cloud computing technologies. To develop higher education, cloud based systems are attractive as most of the applications are freely accessible, rapid to reply and flexible to roll out to large audience. The cloud services allow the institutions to communicate with each other in a flexible and easy way. They offer a bunch of tools designed to support research activities and to facilitate flexible communication among the researchers. These tools and technologies help in developing the higher education, thus making a positive influence on the world. With the increasing relevance of information technology and global transition towards the knowledge society, the higher education can be enriched by migrating the learning management system to cloud. Thus the cloud computing technologies will have significant impact on teaching and learning environment in higher Education.

\section{Conclusions}

The cloud computing evolution has made innovative applications which support teachers and students to a great extent. Abundant education structures have been proposed in modern years. The activities that use cloud applications in learning process can enhance the virtual and visual skills of the students as well as increase their interest towards their subjects. Apart from this, teachers need to take initiative steps to apply cloud technologies in teaching and learning process. Teachers have to develop their teaching curriculums in order to optimize the usage of cloud applications in teaching. Administrators support is necessary for using cloud technologies in classrooms and laboratories because it needs effective infrastructure. Limited internet access becomes a challenge of using these applications in classrooms and laboratories.

The findings confirmed that the students are more interested in using the social media applications for learning. The hypothetical model predicts the continuous willingness to practice cloud computing services which prevails among both the IT and non-IT students in a private university in Chennai. This study infers that it is vital to confirm that cloud applications encourage the higher 
continuous intention in student's learning process. It is also vital that students from non-IT background are also being educated and furnished with fundamental knowledge in IT along with their education procedure which increases their self-assurance in consuming the cloud applications to enrich throughput in learning. Findings illustrates that students are fascinated in consuming the cloud applications for learning, they are moving towards the present age of technological advancements. For generalizing the research, the students from other universities can be considered. The suggestion for future studies is to predict the academic performance of the students using cloud technologies.

\section{REFERENCES}

[1] AnthonyT.Velte, Toby J.Velte, Robert Elsenpeter, Cloud Computing A Practical Approach, McGraw-Hill Companies, New York, 2010.

[2] Ban Salman Shukur, Mohd Khanapi Abd Ghani, M.A Burhanuddin. A Cloud Computing Framework for Higher Education Institutes in Developing Countries (CCF_HEI_DC), International Conference on Intelligent and Interactive Computing IIC2018, Melaka, Malaysia, 2018.

[3] Elizabeth MULI, James KIMUTAI. Adoption of Cloud Computing for Education in Kenyan Universities: Challenges and Opportunities. International Journal of Advanced Research in Computer Engineering \& Technology (IJARCET), Vol. 4, No. 6, 2854-2860, 2015.

[4] Fitore Kostanica, Adel Ben Youssef, Adelina Zeqiri. $1^{\text {st }}$ International Scientific Conference on Knowledge Based Society as a Strategy for Faster Economic Growth, Faculty of Economics, University of Prishtina, 2018.

[5] Garima Rastogi, Hemraj Verma and Rama Sushil. Determining Factors influencing cloud services Adoption in India. Serbian Journal of Management, Vol. 13, No. 2, 335 352, 2017.

[6] Hoong-Cheng Soong, Norazira Binti A Jalil, Ramesh Kumar Ayyasamy, Rehan Akbar. The Essential of Sentiment Analysis and Opinion Mining in Social Media. IEEE 9th Symposium on Computer Applications \& Industrial Electronics (ISCAIE), 2019, Online available from https://sci-hub.tw/https://ieeexplore.ieee.org/abstract/docum ent/8743799

[7] Ibrahim Arpaci. Understanding and predicting student's intention to use mobile cloud storage services. Computers in Human Behavior, Vol. 58, 150-157, 2016.

[8] Jewan Singh, Vibhakar Mansotra. Factors affecting cloud computing adoption in the Indian school education system. Education and Information Technologies, 2019, Online available from https://doi.org/10.1007/s10639-019-09878-3

[9] Kamisli Ozturk.Z, Erzurum Cicek. Z.İ. and Ergul. Z. Sentiment Analysis: An Application to Anadolu University. Special issue of the 3rd International Conference on Computational and Experimental Science and Engineering
(ICCESEN), Vol. 132, 753-755, 2016. DOI: 10.12693/APhysPolA.132.753.

[10] Lillian-Yee-Kiaw Wang, Sook-Ling Lew, Siong-Hoe Lau, Meng-Chew Leow. Usability factors predicting continuance of intention to use cloud e-learning application. Heliyon, Vol. 5, No. 6, 2019, Online available from https://doi.org/10.1016/j.heliyon.2019.e01788

[11] Manjeet Singh Jamwa and Chitranjan Jamwal. Cloud Computing for E-learning. Advances in Computer Science and Information Technology (ACSIT), Vol. 2, No. 8, 26-29, 2015.

[12] Maroof Naieem Qadri, SMK Quadri. A Study of Mapping Educational Institute with Cloud Computing. International Journal of Scientific Research in Computer Science, Engineering and Information Technology, Vol. 2, No. 6, 59-66, 2017.

[13] Mark Stieninger, Dietmar Nedbal, Werner Wetzlinger, Gerold Wagner and Michael A. Erskine. Factors influencing the organizational adoption of cloud computing: a survey among cloud workers. International Journal of Information Systems and Project Management, Vol. 6, No. 1, 5-23, 2017, Online available from https://www.sciencesphere.org/ijisp m/archive/ijispm-060101.pdf

[14] Mohammad Kayali, Nurhizam Safie, Muriati Mukhtar. The Effect of Individual Factors Mediated by Trust and Moderated by IT Knowledge on Students' Adoption of Cloud Based E-learning. International Journal of Innovative Technology and Exploring Engineering (IJITEE), Vol. 9, No. 2, 987-993, 2019.

[15] Muhammad Mannir Ahmad Getso, Riyaz Ahmed A. H. Applications of Cloud Computing in Academic Institutions. International Journal of Information Systems and Engineering (online), Vol. 2, No. 1, 65-72, 2019.

[16] Nabeela Altrabsheh, Mohamed Medhat Gaber, Mihaela Cocea. SA-E: Sentiment Analysis for Education. Conference Paper in Frontiers in Artificial Intelligence and Applications, 2014.

[17] Palaniappan. S. Cloud Computing for Academic Environment. International Journal of Computer Science and Mobile Computing, Vol. 3, No. 5, 8-15, 2014.

[18] Raed Alsufyani, Fash Safdari and Victor Chang. Migration of Cloud Services and Deliveries to Higher Education. In Proceedings of the 2nd International Workshop on Emerging Software as a Service and Analytics (ESaaSA), 86-94, 2015. DOI: $10.5220 / 0005528500860094$

[19] Rui Song, Zhiyi Xiao, Jinjiao Lin and Ming Liu. CIES: Cloud-based Intelligent Evaluation Service for video homework using CNNLSTM network. Journal of Cloud Computing: Advances, Systems and Applications. Vol. 9, No. 7. 1-9, 2020, Online available from https://doi.org/10.1186/s13677-020-0156-5

[20] Sudeepa. R, Dr. Guruprasad. H.S. Resource Allocation in Cloud Computing. International Journal of Modern Communication Technologies \& Research (IJMCTR), Vol. 2, No. 4, 19-21, 2015.

[21] Tanweer Alam, Mohamed Benaida. Blockchain and Internet of Things in Higher Education. Universal Journal of Educational Research, Vol. 8, No. 5, 2164 - 2174, 2020. DOI: 
10.13189/ujer.2020.080556.

[22] Thamer Al-Rousan and Hasan Abu Al Ese. Impact of Cloud Computing on Educational Institutions: A Case Study. Recent Patents on Computer Science, Vol. 8, No. 2, 2019.

[23] Wen-Lung Shiau Patrick Y.K. Chau. Understanding behavioral intention to use a cloud computing classroom: a multiple model comparison approach. Information and
Management, 2016, Online available fromhttp://dx.doi.org/ 10.1016/j.im.2015.10.004

[24] Yousef A. M. Qasem, Rusli Abdullah, Yusmadi Yah Jusoh, Rodziah Atan and Shahla Asadi. Cloud Computing Adoption in Higher Education Institutions: A Systematic Review. IEEE Access, Vol. 7, 63722-63744, 2019. DOI:10.1109/ACCESS.2019.2916234 